Donohue, D. K. (2021). Culture, Cognition, and College: How Do Cultural Values and Theories of Intelligence Predict Students' Intrinsic Value for Learning?

\title{
Culture, Cognition, and College: How Do Cultural Values and Theories of Intelligence Predict Students' Intrinsic Value for Learning?
}

\author{
Dana K. Donohue* \\ Northern Arizona University \\ *Corresponding Author: dana.donohue@gmail.com \\ Received : 2019-09-07 \\ Rev. Req. : 2019-12-14 \\ Accepted : 2020-01-09
}

doi) $10.46303 /$ jcve.2020.3

\begin{abstract}
How to cite this paper: Donohue, D. K. (2021). Culture, Cognition, and College: How Do Cultural Values and Theories of Intelligence Predict Students' Intrinsic Value for Learning?, Journal of Culture and Values in Education, 4(1), 1-14, https://doi.org/10.46303/jcve.2020.3

\section{Abstract}

This research explored the cultural and cognitive factors that promoted college students' intrinsic value for academic learning, which has been shown to be an important correlate of college students' GPA. Cultural values and theories of intelligence were both hypothesized to predict students' intrinsic value, but only cultural values were shown to be an important predictor in these relationships. Explanations and implications for these findings are explored.

Keywords: Cultural Values; Theories of Intelligence; Intrinsic Value for Learning

\section{Introduction}

With travel, migration, and technology, people are exposed to individuals from different cultural backgrounds in their school, work, and home lives. Culture influences the goals that people set, why they set goals, and the degree of motivation they put forth to achieve those goals. For example, when cross-country comparisons are made for science and math achievement, secondary school students in collectivist countries like Japan, Hong Kong, and South Korea consistently outperform students in the United States (Leung, 2002). These achievement differences have been attributed, in part, to cultural values that differ in their emphasis on the importance of education and the effort it takes to achieve (Zha, Walczyk, Griffith-Ross, Tobacyk, \& Walczyk, 2006). People in collectivist countries, like those in Asia, tend to subscribe to theories of intelligence that view intelligence as more malleable than do people in places like the United States (Heine et al., 2001; Mizokawa \& Ryckman, 1990). Those who 
Donohue, D. K. (2021). Culture, Cognition, and College: How Do Cultural Values and Theories of Intelligence Predict Students' Intrinsic Value for Learning?

adhere to malleable theories have been shown to put more time and effort into their studies because they view intelligence as something that can be enhanced through academic work (Blackwell, Trzesniewski, \& Dweck, 2007).

People vary in their cognitive strategies and value for learning. Those who intrinsically value learning have higher motivation and self-efficacy, which can be important for academic achievement (Wang \& Guthrie, 2004; Wigfield \& Guthrie, 1997). This research explores the cultural and cognitive factors that promote students' intrinsic value for academic learning, which has been shown to be an important correlate of college students' GPA (Richardson, Abraham, \& Bond, 2012). Vygotsky's (1978) sociocultural learning theory provides the theoretical paradigm for cultural values' influence on intrinsic value for learning. Vygotsky suggested that learning is strongly influenced by people's culture because it determines the important things to learn about in people's environments. Dweck and Leggert's (1988) socialcognitive theory of motivation provides a competing explanation for students' intrinsic value for learning. They suggested that people differ in their theories about intelligence and how it is formed; these beliefs subsequently affect how people strategize about learning and achievement. The focus of this research is whether cultural values or theories of intelligence was a stronger predictor of college students' intrinsic value for learning.

\section{Cultural Values}

Culture can be conceptualized as a group's values and beliefs that influence their behavior and goals. People interact in a variety of cultures in their daily lives; depending on what they do, these could include "university culture," "work/corporate culture," as well as the culture of different sports and activities in which they participate (e.g., "yoga culture") (Endicott, Bock, \& Narvaez, 2003). Culture has been linked with intrinsic motivation. When comparing American and Asian children in studies of personal choice for anagram tasks and how it influenced their intrinsic motivation to complete these tasks, lyengar and Lepper (1999) found that freedom of choice had more of an influence on American children's intrinsic motivation for tasks than it did for Asian children's intrinsic motivation. These findings suggest that culture can affect cognition.

People are often formally and informally socialized to act and embrace values in accordance with their culture (Chiu \& Chow, 2010; Vygotsky, 1978). These cultural values can influence academic thoughts like whether learning is a worthwhile endeavor. Ethnic cultural values both between and within countries are often studied through the individualism-collectivism paradigm, where people give priority to either individual goals or the goals of the group (Triandis, 1996). When considering school performance, Chiu and Chow (2010) suggest that students who belong to a collectivist culture may have higher intrinsic value for achievement because they view it as a way to obtain success for the group; moreover, when academically struggling, they seek help and learn from one another, which may boost their individual performance. The paramount role of family in collectivist cultures also may influence ideas 
Donohue, D. K. (2021). Culture, Cognition, and College: How Do Cultural Values and Theories of Intelligence Predict Students' Intrinsic Value for Learning?

about the importance of learning. Different terms have been used in the literature to explain why family obligation drives achievement, including "relative functionalism" for Asians (Sue \& Okazaki, 1990) and "familismo" for Latino Americans (Taggart, 2018). Conversely, commitment to family can undermine academic achievement. For example, sometimes the obligation of "family first" drives Latino adolescents to eschew attending college in order to begin contributing to family finances immediately after high school (Stein et al., 2014). Indeed, duties to the family and/or group may be a source of stress for people with collectivist mindsets.

Individualist values have been linked with achievement goals. In cross-cultural research between Denmark and the United States, both countries were ascribed individualist values, but the values of Denmark were considered more egalitarian (i.e., horizontal individualism) whereas the values of the United States were deemed more competitive (i.e., vertical individualism) (Nelson \& Shavitt, 2002). The adult participants from both countries were asked questions about the importance of life achievement goals such as the desire for achievement, power, tradition, conformity, and security. Americans reported more adherence to the importance of achievement goals and valued achievement more when compared to the responses of Danes, who reported more value in humbleness.

Cultural values have also been differentiated in terms of hierarchy (i.e., verticalism) versus equality (i.e., horizontalism) (Triandis \& Gelfand, 1988). It has been suggested that more egalitarian cultural views can promote achievement through smaller perceived status differences and more equal learning opportunities for students (Chiu \& Khoo, 2003). Also a potential motivator, verticalism may exert positive effects on achievement-related cognitions through a desire to be on the top of the hierarchy and viewing academic achievement as a means to accomplish this.

In sum, cultural values can influence the value placed on academic learning through the values that are formally and informally instilled in people (Vygotsky, 1978). Both individualistcollectivist and vertical-horizontal values may promote or impede behaviors that foster achievement. People who adhere to collectivism may value learning because of their dedication to group and family values as well as a propensity to seek academic help when needed. Students who identify as individualistic also may have values that can enhance value for learning; feelings of competition, autonomy, and a desire to be "the best" may promote their desire to learn and achieve.

\section{Theories of Intelligence}

Theories of intelligence can be "entity" or "incremental"; entity theorists see intelligence as a fixed trait, whereas incremental theorists see it as something that can grow with effort (Dweck \& Leggett, 1988). Research suggests that students of different ages from various backgrounds who hold incremental views of intelligence have higher achievement than those who hold entity views (Aronson, Fried, \& Good, 2002; Blackwell et al., 2007; Dweck \& Leggett, 1988; 
Donohue, D. K. (2021). Culture, Cognition, and College: How Do Cultural Values and Theories of Intelligence Predict Students' Intrinsic Value for Learning?

Henderson \& Dweck, 1990; Robins \& Pals, 2002).The reasons for this are myriad, including more positive expectations for effort and thus more effort-based strategies for success, fewer helpless attributions of behavior, and more intrinsic value for academic learning (Blackwell et al., 2007). Incremental theorists take the stance that everyone, no matter their current intellectual ability, has room to grow (Aronson et al., 2001). In this research, incremental theories of intelligence were expected to positively predict intrinsic value for learning.

\section{Intrinsic Value for Learning}

Pintrich and DeGroot (1990) suggest that students' achievement motivation involves several components, including their achievement goals and beliefs about whether achievement is of value; intrinsic value encompasses people's answers for "Why am I doing this task?" (p. 36). Those who place high intrinsic value for learning will engage in more cognitive and selfefficacious achievement strategies than those with lower intrinsic value (Credé and Phillips, 2011; Pintrich \& DeGroot, 1990). Students with high intrinsic value, motivation, and selfregulation have higher achievement outcomes than students who do not engage in these thoughts and behaviors (Schunk \& Zimmerman, 1994). For these reasons, the factors that predict intrinsic value for learning were explored.

\section{Purpose}

The aim of this research is to determine whether cultural values (Vygotsky, 1978) or theories of intelligence (Dweck \& Leggert, 1988) more strongly predicted college students' intrinsic value for learning. Cultural values have been suggested to influence behaviors like intrinsic value for learning, for example, as a means of success for the family and the group (Chiu \& Chow, 2010). Theories of intelligence similarly have been suggested to influence intrinsic value through their influence on beliefs about the sources of intelligence as fixed or malleable (Blackwell et al., 2007). The competing hypotheses were exploratory because there was no previous research indicating which should be a more powerful predictor.

H1: Cultural values will predict intrinsic value for learning.

$\mathrm{H} 2$ : Incremental theories of intelligence will predict intrinsic value for learning.

H3: Cultural values and theories of intelligence will correlate.

\section{Method}

\section{Participants}

The participants in this study were 1,094 undergraduates at a university in the southwestern United States. Participants ranged from 18 to 49 years of age $(M=18.91, S D=2.26)$, with $n=$ 236 males, $n=849$ females, and $n=9$ stated they preferred not to disclose their gender. In terms of ethnicity, $n=255$ identified as Latino, $n=630$ White, $n=58$ Black or African American, 
Donohue, D. K. (2021). Culture, Cognition, and College: How Do Cultural Values and Theories of Intelligence Predict Students' Intrinsic Value for Learning?

$\mathrm{n}=46$ Native American, $\mathrm{n}=42$ Asian, $\mathrm{n}=19$ Pacific Islander, $\mathrm{n}=5$ Middle Eastern, and $\mathrm{n}=39$ identified as "other." Because the data were collected online and participants were forced to answer one question before moving on to the next, there were no missing data.

\section{Measures}

Individualism and Collectivism Scale (Triandis \& Gelfand, 1998). The Individualism and Collectivism Scale is a nine-point Likert scale ranging from strongly disagree to strongly agree. Individualism and collectivism, conceptualized as orthogonal constructs in this measure, can emphasize equality (termed "horizontal") or hierarchy (termed "vertical") (Triandis \& Gelfand, 1998). For example, those high in individualism can desire to be unique but not of higher status than others (e.g., horizontal individualism; characteristic of Sweden) and/or want to be unique and superior to others (e.g., vertical individualism; characteristic of the United States). Those high in collectivism can emphasize the goals and equality of the group (e.g., horizontal collectivism; characteristic of the Israeli kibbutz) or, as is the case with vertical collectivism, be attuned to the group, but with differential social statuses among group members, like with the caste system in India (Singelis, Triandis, Bhawuk, \& Gelfand, 1995; Triandis \& Gelfand, 1998). It contains four subscales: 1) Horizontal individualism (e.g., I'd rather depend on myself than others), 2) Vertical individualism (e.g., Winning is everything), 3) Horizontal collectivism (e.g., I feel good when I cooperate with others), 4) Vertical collectivism (e.g., Parents and children must stay together as much as possible). The items for each subscale are summed to calculate subscale totals. For this research, Horizontal individualism $\alpha=.70$, Vertical individualism $\alpha=.68$, Horizontal collectivism $\alpha=.72$, Vertical collectivism $\alpha=.72$.

Motivated Strategies for Learning Questionnaire (Pintrich \& DeGroot, 1990). The MSLQ is a 44item self-report measure that utilizes a seven-point Likert scale ( $1=$ not at all true of me, to 7 = very true of me) to measure students' motivation orientation for learning and self-regulated strategy use. This version of the MSLQ has five subscales: Intrinsic Values, Self-Efficacy, Test Anxiety, Cognitive Strategies, and Self-Regulation, where the items are summed to compute subscale totals. The Intrinsic Value subscale was used for this research with $\alpha=.81$.

Implicit Theories of Intelligence (Dweck, 1999). Theories of intelligence were assessed using Dweck's eight-item scale. The items comprise four questions that tap incremental (malleable) and four questions that tap entity (fixed) theories of intelligence. Participants respond on a fivepoint Likert scale. In order to calculate score totals, the four incremental items are reverse scored; all items are then summed and averaged. Higher scores suggest adherence to more fixed intelligence beliefs. For this research, full scale $\alpha=.89$.

\section{Procedure}

This study was approved by the IRB board at the university at which the research occurred. The data were collected over two academic semesters. Undergraduate students who were enrolled 
Donohue, D. K. (2021). Culture, Cognition, and College: How Do Cultural Values and Theories of Intelligence Predict Students' Intrinsic Value for Learning?

in a psychology class signed up to participate in this online study. When the students were ready, they signed in to the study and were brought to an online data collection program (i.e., Qualtrics). The participants were provided an informed consent that explained the general purpose of the study and were informed that it would take about 30-45 minutes to respond to all of the items. When they had completed the questionnaires, the students were provided a debriefing where they were provided a more specific purpose of the study and were given the contact information of the primary investigator if they had any questions or concerns.

\section{Results}

\section{Statistical Analyses}

Structural equation modeling was used for the primary analyses because it provided a method of analyzing latent variables (indicated by a circle in the figure) with measured variables (indicated by rectangles) in one analysis. Latent variables are constructs that cannot be directly measured but are constructed with multiple measured variables. In this analysis, cultural values was a latent variable, with four measured variables as its indicators: horizontal collectivism, vertical collectivism, horizontal individualism, and vertical individualism. Theories of intelligence and intrinsic value for learning were both measured variables. Preliminary analyses were conducted using SPSS 25.0, and SEM analyses were conducted using AMOS 21.0 (Arbuckle, 2012).

First, to determine whether the questionnaires were internally consistent, alpha coefficients were computed for each scale (see alphas in Measures). Internal consistency indicates when participants are responding to the items in a questionnaire in a way that is consistent and is one method of determining whether a questionnaire is an appropriate way to measure the construct of interest. The alphas for the cultural values subscales were somewhat low, ranging from $\alpha=.68-.72$, but these scores are likely low because only four items comprise each subscale. Data were then checked for normality of the distributions; normal distributions allow for certain statistical analyses whereas non-normal distributions require different statistical analyses. Values for skewness (whether the distribution tilted to the left or the right) ranged between -.013 and -.397, and the values for kurtosis (whether the distribution was peaked or flat) ranged from .000 to -.600 , which are considered in an acceptable range for normality (George \& Mallery, 2001). However, the Shapiro-Wilk test indicated non-normality of distributions for each of the measured variables ( $W=.954-.996, p<.01)$. For this reason, the structural equation models (SEM) were analyzed with asymptotically distribution-free estimation, which is the appropriate analysis for non-normal distributions. The results of the SEM analyses can be found in Figure 1 and Table 2, while ranges, means, and standard deviations are presented in Table 1.

Table 1 shows that, of the cultural values, horizontal individualism had the highest mean score while vertical individualism evinced the lowest mean score. All of the questionnaires had means 
Donohue, D. K. (2021). Culture, Cognition, and College: How Do Cultural Values and Theories of Intelligence Predict Students' Intrinsic Value for Learning?

in the moderate range and moderate variability, as indicated by the values of the standard deviations. The baseline hypothesized SEM and final SEM are shown in Figure 1, with the post hoc modifications illustrated in bold. Post hoc modifications are changes to the initial model based on the results of the initial analysis. It was hypothesized that cultural values (a latent variable with two collectivism and two individualism indicators) and theories of intelligence were predictors of intrinsic value for learning. The hypothesized model did not fit the data with a $\mathrm{X}^{2}(8)=110.99, \mathrm{p}<.001 ; \mathrm{CFI}=.75, \mathrm{GFI}=.96$, RMSEA $=.11$; RMSEA 90\% Cl: .09 - .13. The standardized residual covariances were examined to determine what alterations could improve model fit. Standardized residual covariances provide values that show which of the variables in the model are preventing the model from reaching a good fit and guide the subsequent post hoc modifications. The standardized residual covariances revealed that vertical individualism was problematic for model fit; however, there was concern about modifying the theory underlying the cultural values latent variable based on post hoc, data-driven evidence. The decision was made to keep vertical individualism in the model. Next, the modification indices were examined to determine if there were minor, theoretically sensible changes that could improve fit. Correlating the error covariances for the individualism variables and the collectivism variables was theoretically sensible and would improve model fit. Error variances are variances in the measured variables that are not related to the latent factors; when they correlate with one another, they are called error covariances. When these two error covariances were added, model fit improved to a more acceptable range with $X^{2}(6)=37.67, p$ $<.001 ; \mathrm{CFI}=.92, \mathrm{GFI}=.99$, RMSEA = .07; RMSEA 90\% Cl: .05 - .09.

The direct and total effects of the SEM and the correlations and factor loadings can be seen in Table 2. The bottom row of Table 2 shows how much theories of intelligence $(\boldsymbol{\beta}=.01 p>.05)$ and cultural values $(\boldsymbol{\beta}=.71, p<.01)$ influence intrinsic value for learning, with an $R 2$ of .50. This indicates that about half of the variability in intrinsic value was accounted for by these two predictors, but mainly by cultural values.

Table 1. Ranges, means, and standard deviations among variables in the model $(N=1094)$

\begin{tabular}{|l|l|l|l|}
\hline Observed variable & Range & Mean & Standard deviation \\
\hline Horizontal Ind & $9-36$ & 27.65 & 5.12 \\
\hline Vertical Ind & $5-36$ & 20.73 & 5.75 \\
\hline Horizontal Coll & $6-36$ & 26.68 & 4.92 \\
\hline Vertical Coll & $6-36$ & 26.87 & 5.43 \\
\hline Intrinsic value & $9-63$ & 48.37 & 9.00 \\
\hline
\end{tabular}


Donohue, D. K. (2021). Culture, Cognition, and College: How Do Cultural Values and Theories of Intelligence Predict Students' Intrinsic Value for Learning?

Theories of Int
$1-5.75$
2.60 .90

Figure 1. Hypothesized model and final model with post hoc modifications of correlated error variances in bold. $\mathrm{X}^{2}(6)=37.67, \mathrm{p}<.001 ; \mathrm{CFI}=.92, \mathrm{GFI}=.99$, RMSEA = .07; RMSEA $90 \mathrm{Cl}$ : .05 09.

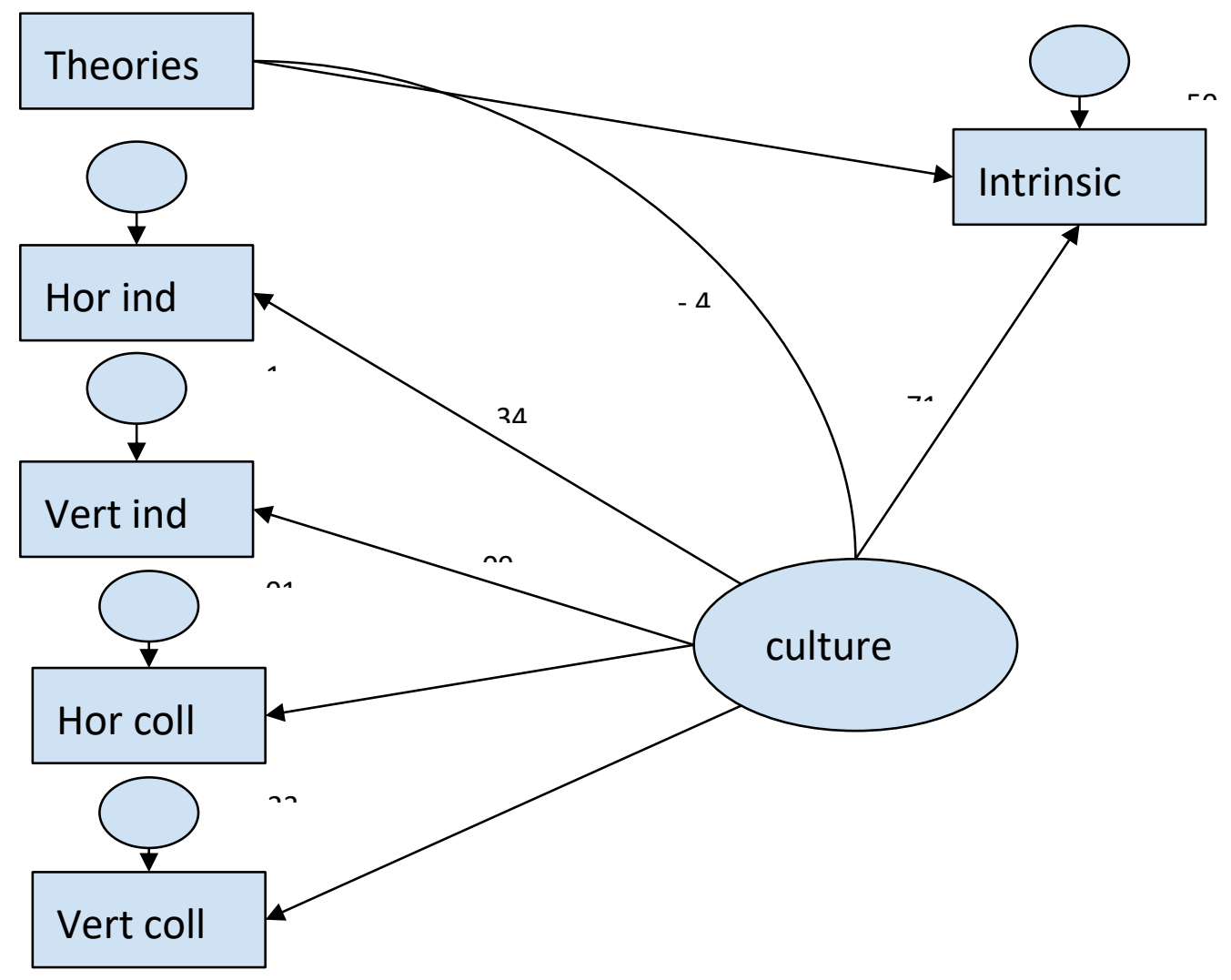

Table 2. Direct/total effects for structural equation model (SEM; $N=1094$ )

\begin{tabular}{|l|l|l|l|l|l|}
\hline Model & $\boldsymbol{\beta}$ & B & $\boldsymbol{\beta}$ & B & \\
\hline & \multirow{2}{*}{ Theories of Intelligence } & Cultural Values & R2 \\
\cline { 1 - 3 } $\begin{array}{l}\text { Direct/Total } \\
\text { Effects }\end{array}$ & & & \\
\hline
\end{tabular}


Donohue, D. K. (2021). Culture, Cognition, and College: How Do Cultural Values and Theories of Intelligence Predict Students' Intrinsic Value for Learning?

\begin{tabular}{|l|l|l|l|l|l|}
\hline Hor Ind & .00 & .00 & .34 & 1.13 & .12 \\
\hline Vert Ind & .00 & .00 & -.09 & -.32 & .01 \\
\hline Hor Coll & .00 & .00 & .48 & 1.54 & .23 \\
\hline Vert Coll & .00 & .00 & .28 & 1.00 & .08 \\
\hline Int Value & .01 & .10 & .71 & 4.17 & .50 \\
\hline
\end{tabular}

\section{Correlations and Factor Loadings}

The correlation between cultural values and theories of intelligence was $(r=-.42,<.01)$, which indicated that cultural values were associated with incremental theories of intelligence (see Figure 1). In Table 2, it can be seen that on the Cultural Values latent variable, both horizontal collectivism $\left(\beta=.48, p<.01, r^{2}=.23\right)$ and horizontal individualism $\left(\beta=.34, p<.01, r^{2}=.12\right)$ loaded more strongly than vertical collectivism $\left(\beta=.28, p<.01, r^{2}=.08\right)$ and vertical individualism $\left(\beta=-.09, p<.05, r^{2}=.01\right)$. This means that, rather than individualism or collectivism, the horizontal component of cultural values comprised the Cultural Values latent variable the most.

\section{Discussion}

It was hypothesized that both cultural values and theories of intelligence would predict intrinsic value for learning, but which would be a stronger predictor was unknown. A model was developed to explain these relationships where both variables were analyzed simultaneously to determine if one was a stronger predictor than the other. While slight post hoc modifications were made in order to improve model fit, the final model suggested that cultural values were a strong predictor of intrinsic value for learning whereas theories of intelligence were not.

Cultural values accounted for about half of the variability in intrinsic value, which means that students' cultural value backgrounds made a substantial contribution to their beliefs about whether learning was a meaningful endeavor or not. These values are likely instilled at an early age, both through formal (e.g., parental teachings) and informal (e.g., role models) means (Vygotsky, 1978). This finding refutes previous research that found that cultural values were not related to achievement or achievement-related motivations (Chiu \& Chow, 2010). However, there were substantial differences in how cultural values were measured between these two studies. In their research, Chiu and Chow (2010) assigned cultural values to each of the 41 countries they assessed. Then, based on these cross-cultural (i.e., cross-country) differences, it was assessed whether cultural values influenced student achievement and achievement values. Although there are often broad differences between countries in their cultural values, this methodological approach of assigning cultural values can be problematic because 1 ) there is 
Donohue, D. K. (2021). Culture, Cognition, and College: How Do Cultural Values and Theories of Intelligence Predict Students' Intrinsic Value for Learning?

considerable variability in culture and cognition within countries, and 2) cultural values are being assigned rather than directly measured. Without direct measurement of cultural values, a more appropriate interpretation of Chiu and Chow's (2010) findings may be that very broad cultural differences between countries do not account for variability in students' achievement and achievement goals between these countries.

Theories of intelligence had no significant influence on students' intrinsic value for learning, which refutes previous research (Dupeyrat \& Marine, 2005; Robins \& Pals, 2002) examining theories of intelligence in college student samples. Robins and Pals (2002) found that theories of intelligence "...were related to the goals individuals pursue in college as well as to their attributions, emotions, and behavioral responses to challenging academic circumstances" ( $p$. 329). When examining adults returning to college, Dupeyrat and Marine (2005) found no influence of incremental (i.e., malleable) theories of intelligence on academic goals, but did find that students' entity (i.e., fixed) theories of intelligence negatively predicted academic goals related to mastering the learning content. Thus, students only reported a desire to master the content when they did not believe in fixed intelligence, but this same desire was not evident for those who believed in malleable intelligence.

In this study, theories of intelligence may have not evinced an effect on college students' intrinsic value for learning because cultural values was a variable in the model that was competing for the variance in intrinsic value. Once theories of intelligence and cultural values were both conceptualized as predictors, cultural values was a stronger predictor. Perhaps theories of intelligence have more influence on other indicators of achievement or achievement-related cognitions, like students' GPA or attributions for failure (Hong, Chiu, Dweck, Lin, \& Wan, 1999).

The factor loadings for the cultural values latent variable indicated that the horizontalism was an important part of cultural values. Horizontally construed cultural values emphasize equality in both individualist and collectivist values: horizontal individualists value an egalitarian autonomy (e.g., socialist ideology) and horizontal collectivists value the equality of their group/community (e.g., communal ideology). To a lesser degree, vertical collectivism contributed to the cultural values latent variable. Vertical collectivism is sometimes referred to as "familism" in the literature (e.g., Gaines et al., 1997) because of its emphasis on the importance of the family.

Vertical individualism was the least important indicator for the cultural values latent variable (in terms of factor loadings) and was the only indicator to load negatively. Unlike the other three cultural values, vertical individualism emphasizes competition and a desire to be the best. These results suggest that there are commonalities between the two horizontal cultural values along with vertical collectivism, which emphasizes hierarchy but within the family structure. Vertical individualism may be a more distinct cultural variable in comparison to the other three values. 
Donohue, D. K. (2021). Culture, Cognition, and College: How Do Cultural Values and Theories of Intelligence Predict Students' Intrinsic Value for Learning?

A negative correlation between theories of intelligence and cultural values was found, which means that cultural values were associated with incremental theories of intelligence (rather than entity theories of intelligence). The cultural values latent variable was largely egalitarian and familial in nature, and this corresponds with findings in the literature linking incremental theories and collectivist beliefs (Heine et al., 2001; Mizokawa \& Ryckman, 1990). Thus, college students who reported that intelligence can be enhanced with effort were more likely to adhere to cultural beliefs that were horizontally construed and family-oriented.

\section{Limitations and Future Directions}

There were limitations to this research. One limitation is that the sample was restricted to college students at one university in the Southwest. Although the sample was relatively ethnically diverse, the generalizability of the results to students of other ages and at other universities may be limited. Another limitation is the self-report nature of the data. Participants may have been less inclined to state that learning holds little intrinsic value to them, knowing that they were participating in a university research study. However, the nature of this type of research (e.g., assessing people's values) most often relies on self-report data.

Future research may want to establish causality between the relationship between cultural values and intrinsic value for learning. Research that has experimentally primed either entity or incremental theories of intelligence in children found that these beliefs influenced students' learning goals (Bempechat, London, \& Dweck, 1991) and attributions for failure (Hong et al., 1999). In an experiment that manipulated cultural values (Kogut, Slovic, \& Västfjäll, 2015), priming an individualist or collectivist mindset created a propensity for people to donate to either individuals or groups. Similar experimental research could be used to determine if cultural values cause achievement-related cognitions or are merely associated with them.

\section{Conclusion}

In conclusion, this research suggests that cultural values were a stronger predictor of college students' intrinsic value for learning when compared to theories of intelligence. This suggests that cultural considerations should be made when trying to promote the academic achievement of college students. Because education is vital for upward mobility for cultures around the world, understanding the factors that can foster positive academic experiences for students of all backgrounds should continue to be explored.

\section{References}


Donohue, D. K. (2021). Culture, Cognition, and College: How Do Cultural Values and Theories of Intelligence Predict Students' Intrinsic Value for Learning?

Aronson, J., Fried, C. B., \& Good, C. (2002). Reducing the effects of stereotype threat on African American college students by shaping theories of intelligence. Journal of Experimental Social Psychology, 38, 113-25.

Arbuckle, J. L. (2012). IBM SPSS Amos, 21 users' guide. Chicago, IL: Amos Development Corporation.

Bempechat, J., London, P., \& Dweck, C. S. (1991). Children's conceptions of ability in major domains: An interview and experimental study. Child Study Journal, 21, 11-36.

Blackwell, L. S., Trzesniewski, K. H., \& Dweck, C. S. (2007). Implicit theories of intelligence predict achievement across an adolescent transition: A longitudinal study and an intervention. Child Development, 78, 246-263.

Bronfenbrenner, U. (1979). The ecology of human development: Experiments by nature and design. Cambridge, MA: Harvard University Press.

Chiu, M. M., \& Chow, B. W. Y. (2010). Culture, motivation and reading achievement: High school students in 41 countries. Learning and Individual Differences 20, 579-592.

Chiu, M. M., \& Khoo, L. (2003). Rudeness and status effects during group problem solving: Do they bias evaluations and reduce the likelihood of correct solutions? Journal of Educational Psychology, 95, 506-523.

Credé, M., \& Phillips, L. (2011). A meta-analytic review of the motivated strategies for learning questionnaire. Learning and Individual Differences, 21, 337-346.

Deci, E. L., \& Ryan, R. M. (1985). The general causality orientations scale: Self-determination in personality. Journal of Research in Personality, 19, 109-134.

Dupeyrat, C., \& Marine, C. (2005). Implicit theories of intelligence, goal orientation, cognitive engagement, and achievement: A test of Dweck's model with returning to school adults. Contemporary Educational Psychology, 30, 43-59.

Dweck, C. S. (1986). Motivational processes affecting learning. American Psychologist, 41, 1040-1048.

Dweck, C. S. (1999). Self-theories: Their role in motivation, personality, and development. Philadelphia: Psychology Press.

Dweck, C. S., \& Leggett, E. L. (1988). A social-cognitive approach to motivation and personality. Psychological Review, 95, 256-273.

Endicott, L, Bock, T., \& Narvaez, D. (2003). Moral reasoning, intercultural development, and multicultural experiences: Relations and cognitive underpinnings. International Journal of Intercultural Relations, 27, 403-419. 
Donohue, D. K. (2021). Culture, Cognition, and College: How Do Cultural Values and Theories of Intelligence Predict Students' Intrinsic Value for Learning?

Gaines, S. O., Marelich, W. D., Bledsoe, K. L., Steers, W. N., Henderson, M. C., Granrose, C. S., et al. (1997). Links between race/ethnicity and cultural values as mediated by racial/ethnic identity and moderated by gender. Journal of Personality and Social Psychology, 72, 14601476.

George, D., \& Mallery, P. (2001). SPSS for Windows. Boston: Allyn and Bacon.

Heine, S. J., Kitayama, S., Lehman, D. R., Takata, T., Ide, E., Leung, C., et al. (2001). Divergent consequences of success and failure in Japan and North America: An investigation of selfimproving motivations and malleable selves. Journal of Personality and Social Psychology, 81, 599-615.

Henderson, V. L., \& Dweck, C. S. (1990). Motivation and achievement. In S. S. Feldman \& G. R. Elliott (Eds.), At the threshold: The developing adolescent (pp. 308-329). Cambridge, MA: Harvard University Press.

Hong, Y., Chiu, C., Dweck, C. S., Lin, D., \& Wan, W. (1999). Implicit theories, attributions, and coping: A meanings system approach. Journal of Personality and Social Psychology, 77, 588599.

Iyengar, S. S., \& Lepper, M. R. (1999). Rethinking the value of choice: A cultural perspective on intrinsic motivation. Journal of Personality and Social Psychology, 3, 349-366.

Kogut, T., Slovic, P., \& Västfjäll, D. (2015b). Scope insensitivity in helping decisions: Is it a matter of culture and values? Journal of Experimental Psychology: General, 144, 1042-1052. http://dx.doi.org/ 10.1037/a0039708

Leung, F. K. S. (2002). Behind the high achievement of East Asian students. Educational Research and Evaluation, 8, 87-108.

Mizokawa, D. T., \& Ryckman, D. B. (1990). Attributions of academic success and failure: A comparison of six Asian-American ethnic groups. Journal of Cross Cultural Psychology, 21, 434451.

Nelson, M. R., \& Shavitt, S. (2002). Horizontal and vertical individualism and achievement values: A multimethod examination of Denmark and the United States. Journal of Cross Cultural Psychology, 33(5), 439-458.

Pintrich, P. R., \& DeGroot, E. V. (1990). Motivated and self-regulated learning components of classroom academic performance. Journal of Educational Psychology, 82, 33-40.

Richardson, M., Abraham, C., \& Bond, R. (2012). Psychological correlates of university students' academic performance: A systematic review and metaanalysis. Psychological Bulletin, 138(2), 353-387. 
Donohue, D. K. (2021). Culture, Cognition, and College: How Do Cultural Values and Theories of Intelligence Predict Students' Intrinsic Value for Learning?

Robins, R. W., \& Pals, J. L. (2002). Implicit self-theories in the academic domain: Implications for goal orientation, attributions, affect, and self-esteem change. Self and Identity, 1, 313-336.

Schunk, D. H., \& Zimmerman B. J. (Eds.). (1994). Self-regulation of learning and performance. Hillsdale, NJ: Erlbaum.

Singelis, T. M., Triandis, H. C., Bhawuk, D. P. S., \& Gelfand, M. J. (1995). Horizontal and vertical dimensions of individualism and collectivism: A theoretical and measurement refinement. Cross-Cultural Research, 29, 240-275.

Stein, G. L., Cupito, A. M., Mendez, J. L., Prandoni, J., Huq, N., \& Westerberg, D. (2014). Familism through a developmental lens. Journal of Latina/o Psychology, 2(4), 224-250. https://doi.org/10.1037/lat0000025

Sue, S., \& Okazaki, S. (1990). Asian-American educational achievements: A phenomenon in search of an explanation. American Psychologist, 45(8), 913-920. doi: 10.1037/0003066X.45.8.913

Taggart, A. (2018). Latina/o students in K-12 schools: A synthesis of empirical research on factors influencing academic achievement. Hispanic Journal of Behavioral Sciences, 40(4), 448471. https://doi.org/10.1177/0739986318793810

Triandis, H. C. (1996). The psychological measurement of cultural syndromes. American Psychologist, 51, 407-415.

Triandis, H. C., \& Gelfand, M. J. (1998). Converging measurement of horizontal and vertical individualism and collectivism. Journal of Personality and Social Psychology, 74, 118-128.

Vygotsky, L. S. (1978). Mind in society. Cambridge, MA: Harvard University Press.

Wang, J. H. Y., \& Guthrie, J. T. (2004). Modeling the effects of intrinsic motivation, extrinsic motivation, amount of reading, and past reading achievement on text comprehension between U.S. and Chinese students. Reading Research Quarterly, 39, 162-184.

Wigfield, A., \& Guthrie, J. T. (1997). Relations of children's motivation for reading to the amount and breadth of their reading. Journal of Educational Psychology, 89, 420-432.

Zha, P., Walczyk, J., Griffith-Ross, D. A., Tobacyk, J. J., \& Walczyk, D. F. (2006). The impact of culture and individualism-collectivism on the creative potential and achievement of American and Chinese Adults, Creativity Research Journal, 18(3), 355-366. 